\title{
DIVERSIFICATION OF CULTURAL TOURISM: DEVELOPMENT TREND OR THE BEGINNING OF DISAPPEARANCE?
}

\author{
Vukan Vujović \\ University of Donja Gorica, \\ Podgorica, Montenegro
}

Correspondence:

Vukan Vujović

e-mail:

vukan.vujovic@gmail.com

\begin{abstract}
:
Cultural tourism, driven by marked changes at the cultural awareness level and the visitor needs, has been experiencing drastic changes in recent years, both in the way of presenting cultural values and satisfying the widely diverse population of cultural tourists. The aim of this study is to provide an insight into the range of newly formed selective types of the offer, as well as to provide a conceptual background that could serve as a basis for the future research by other authors, with an emphasis on the vulnerability of the elementary concept of cultural tourism, based on diversity and recognition. It also points out to the necessity of setting and solving the problematic issue of further pervasive diversification of cultural programs, at the expense of preserving developmental progress and protecting the connection of cultural contents with true cultural values from the aspect of cultural sustainability. This empirical study emphasizes the importance of separate observing the cultural phenomenon from the overall view of the destination tourist system.
\end{abstract}

Keywords:

cultural tourism, evolutionary cycle, thematic forms, destination value system

\section{INTRODUCTION}

The intense development of culturally inspired motives and the very pronounced expansion of culturally-related destination activities question their true connection with the traditional meaning and essential concept of cultural tourism (Hughes \& Allen, 2005). Whether visitors/tourists, when meeting their own tourist needs, truly adhere to and are guided by traditional principles of cultural convergence, exchange and understanding of diversity; or is it primarily a global technological and modern-civilized backdrop (caprice), without any reliance on subconscious elements and cultural-historical values, but exclusively on leisure and fake created spiritual curiosity instead of a trip / fun? Does the escape from the knowledge of new and experientially unstudied and unknown, actually flee from oneself ...and consequently an unnoticed intellectual downfall or individual spiritual rise / enlightenment? Where does all this ultimately lead to and where it may be the end of such a scenario? ... are just some of the worrying and basic issues that should be posed in current developmental circumstances, but also in the near future.

In attempting to respond to these issues the authors in the field of cultural tourism rely on different approaches and clarification sources. 
While some point out to the conduct of market research in order to reduce the risk of further expanding the diversified experience (Tourism Business Essentials, 2014), others, as the main problem of superficial consumption of cultural tourism products, emphasize the uniform behavior of visitors (Barbieri \& Mahoney, 2010) proposing education of market segments as the solution. Similar considerations are shared by Mc Kercher and Du Cross (2003), claiming that segmentation based activities assume that different thematic attractions lead to the formation of tourist groups, and that weakening the importance of the original form of cultural tourism is before all related to travel decisions primarily for pleasure - which drastically reduces their educational and spiritual component (Urošević, 2012). It is therefore indicating that visitors from culturally distant places are much more motivated and responsible for the maintenance of cultural reasons for visiting, as well as the purpose of the survival of classical cultural tourism, in relation to those from the proximate cultural environment.

\section{CONCEPTUAL BACKGROUND}

The conceptual framework of cultural tourism is based on understanding and knowing of traditional cultural diversities, and as such implies differentiation between the concepts of cultural tourism and cultural tourists. It should be stated that the concept of multiculturalism, as the creation of the modern globalization of tourism products / destinations, represents essential obstacle to the survival of original and autochthonous culture (UNESCO, 2006), which is the only indicator of its true sustainability.

\section{Cultural Tourism - Cultural Tourists}

By observing the phenomenon of cultural tourism as the movement of tourists to cultural attractions and sights away from their place of residence with the intent of meeting cultural tourism needs (Richards, 2001), it is possible to point out that a cultural tourist is a person who is in a constant looking for new intellectual and spiritual values, with high motivation towards experiencing the tourist product of the destination in high specific, i.e. individual sense (Otto \& Ritchie, 1996). In this way, a significance of retaining the cultural identity of the community is indirectly pointed out (Pritchard \& Morgan, 2001) as a driving stimulus for conventional cultural tourism.

In accordance with the highlighted way of thinking, most attempts at the typological classification of cultural tourists (Hughes, 1996; Mc Kercher \& Du Cross, 2002) were based on the classification of determined categories according to the degree / depth of cultural experience or the type of culturally-conditioned needs. By subliming the mentioned methodological principles it is possible to implement certain criteria for cultural tourists' typology (Table 1). These criteria represent a unique combination of psychological-motivational characteristics of visitors and spatial-anthropological features of cultural tourism destination.

Table1. Typology of Cultural Tourists

\begin{tabular}{|c|c|c|}
\hline Criterion & Primary Categories & Secondary Categories \\
\hline \multirow{2}{*}{ 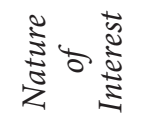 } & Unspecific Cultural Tourists (Type 1) & \\
\hline & Specific Cultural Tourists (Type 2) & \\
\hline \multirow{6}{*}{ 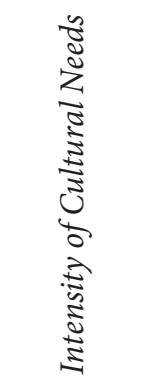 } & \multirow{2}{*}{ Purposeful Cultural Tourist (Type 3) } & Real cultural tourist (3a) \\
\hline & & Commercial cultural tourist ( $3 \mathrm{~b}$ ) \\
\hline & \multicolumn{2}{|l|}{ Serendipitous Cultural Tourist (Type 4) } \\
\hline & \multirow{3}{*}{ Unintentional Cultural Tourist (Type 5) } & Incidental cultural tourist $(5 a)$ \\
\hline & & Casual cultural tourist (5b) \\
\hline & & Sightseeing cultural tourist $(5 c)$ \\
\hline
\end{tabular}

Source: Derived by the author according to Mc Kercher \& Du Cross, 2003 (p. 46) 
The explanation of the classification criterion presented in the first table is the following (Hughes, 1996): unspecific cultural tourists (type 1) visit different countries and participate in different forms of cultural life, showing the general cultural interest. Specific cultural tourists (type 2) are focused on one site or a smaller number of them and visit the specific city or country (looking for a particular type of art or attractions). Their cultural interest is special.

Regarding the second criterion presented, it includes the existence of primary and secondary typological categories. Purposeful cultural tourists (type 3) are inspired by culture, seeking a deep cultural experience, so their cultural needs are of primary character. At this type there are two sub-types of cultural tourists. For real cultural tourists ( $3 a$ ) culture is the basis of motivation, while for commercial cultural tourists ( $3 b$ ) culture is a motive, but only for the most important / famous or so called "must see" category of attractions. Serendipitous cultural tourists (type 4) do not visit the destination because of culture, but they still have a cultural tourism experience in situ. Accordingly, their cultural need is secondary. In the case of unintentional cultural tourists (type 5), the arrival motive is not culture, but something else. In this case, the cultural need is tertiary. Incidental cultural tourists (5a) do not show the motivation for culture, but they still visit some of destination attractions. Casual cultural tourists (5b) have a relatively poor motive for visiting the destination and are satisfied with the superficial information about the culture. Finally, sightseeing cultural tourists $(5 \mathrm{c})$ at least travel for cultural reasons, but their cultural impression is limited only to the superficial experiencing of site attractiveness.

\section{Modern Evolution of Cultural Tourism Forms}

Starting from its original (unifying) social phenomenon, cultural tourism has evolved over the last decades in a wide range of complementary forms and market modulations (ICOMOS, 2002). Part of them come from the original concept of cultural tourism, relying on the historical and anthropogenic properties of tourism resources (OECD, 2009). On the other hand, a significant part of new evolutionary forms represents the unique combination of development trends, accompanied by the increasing indirect involvement of visitors and an ever-more complex experience of destination cultural values (Christou, 2005).

Such diversification of contemporary cultural-related tourism activities has required the need for the systematic way of looking at and thinking about analytical approach to the topic of cultural tourism (Chen \& Rahman, 2018). As the final result of a comprehensive interpretation of these movements, a schematic representation (Figure 1) has been shown, indicating the interconnections and essential connection within the separately isolated forms of cultural tourism.

The presentation points to a high diversification degree of contemporary evolutionary cultural forms, with the still noticeable tendency of the actual increase in diversity and the number of driving cultural motives (as the main preconditions for special tourist trips), in accordance with satisfying the high specific cultural needs (Kay, 2009) - which in the future will condition further classification and endanger the survival of some of the already existing or conventional form itself.

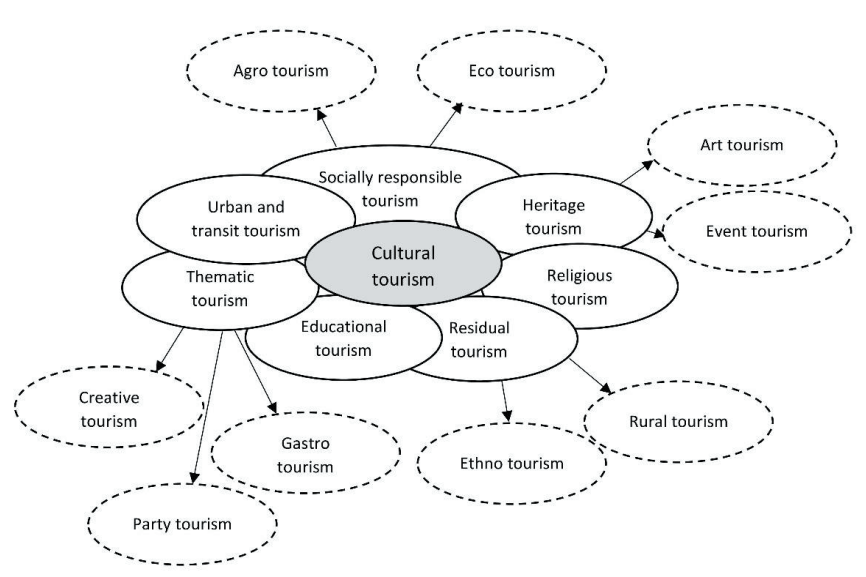


Some of the terminological expressions depicted in the scheme speak in favor of actual divisions, differentiation and conceptual definition of new cultural activities. The strength of the link left behind the original form of cultural tourism varies depending on the nature and character of cultural relation within the new evolutionary forms of multiplied activities (Mc Kercher et al., 2008). Heritage tourism involves visits to historical and architectural monuments or cultural and historical institutions (museums, mausoleums, palaces, etc.) or the so-called "cultural tours" (Domšić, 2013) $\rightarrow 2$ types: art or "immaterial” tourism (interest in reproductive and visual arts); and event or "manifestation / festival" tourism (visiting manifestations and events - folklore, festivals, concerts, etc.).

Religious tourism (Tomljenović \& Dukić, 2017) involves the journey to meet religious needs (visiting shrines, churches, monasteries, temples, etc.). Residual tourism means visiting of socially undeveloped areas / born domestic places, or areas with traditional customs and culture (Yang, 2011) $\rightarrow 2$ types: rural tourism (staying in a rural area for rest); and ethno or "indigenous / Robinson" tourism (visiting rare cultural groups and communities).

Educational or "scientific-research" tourism includes traveling for the purpose of professional and educational training (seeking new knowledge and cognition methods) (Ritchie, 2003). Thematic tourism or tourism with specific motives / needs and ways of their satisfying (Trauer, 2006) $\rightarrow 3$ types: gastro tourism (traveling for enjoying food - national dishes and traditional specialties); party tourism (traveling for fun - casinos, pubs, nightclubs, discos, etc.); and creative or "hobby" tourism (interest in creativity and specific forms of mental and spiritual interest).

Urban tourism includes visiting or road trip to large cities (Ashworth \& Page, 2011). Socially responsible tourism implies any form of tourism (and not only cultural) characterized by a responsible and principally consistent manner of practicing (Medina, 2008) $\rightarrow 2$ types: agro tourism (staying in the agrarian environment with direct inclusion in performing the household activities - i.e. active participation); and eco-tourism (staying in untouched natural environment with respect to ecological principles and not disturbing biodiversity features of the area).

\section{ANALYSIS OF RELATIONS AND CONNECTIONS}

From the presented diversification forms of cultural tourism, the strongest connection is realized between the cultural and heritage tourism, which are sometimes even commonly interpreted under the term cultural heritage tourism (Moscardo, 2001). A somewhat weaker connection of cultural tourism is established with urban tourism, due to the secondary character of cultural needs, although the remaining four forms of primary diversification, starting from socially responsible to educational tourism (excluding heritage and urban tourism) can be considered modalities of thematic tourism.

When it comes to true cultural values placed within the tourist offer, in the first place (besides heritage tourism) are residual and educational form, with appropriate sub forms. The reason for this statement is the implication of broad cultural foundation on a traditional basis. On the other hand, the historical cultural basis is more related to the religious form of tourism (Tala \& Padurean, 2008). Accordingly, the distinction between the traditional and historical cultural basis is that the traditional one is constantly transformed and built, while the historical one is exclusively inherited in the form of initially set ideological platform and established spiritual beliefs. In other words, the historical cultural basis does not possess a real developmental capacity. It is of static character.

Secondary forms of cultural tourism diversification, according to the developmental aspect of genesis, are far more distanced from the initial concept of cultural tourism, but also show a very small amount of conceptual and spatially-manifesting relations or similarities to it. This statement stems from the subconscious motivational component and individual characteristics of visitors (Vana \& Maleascu, 2016), related to their preferences, affinities and enthusiasm directed towards differently created destination cultural program and activities. 
On the basis of the above considered approach and reflections, the issue of new typological categories of cultural tourists and type of their empirical experience is becoming very topical to mitigate developmental consequences from the resulting diversity. This and other similar researches (Benur \& Bramwell, 2015; Weidenfeld, 2018) could contribute to better understanding of the current level of global diversification, which would be beneficial from the aspect of predicting the expansion of culturally-conditioned activities in the destination tourism sector.

The management structures in an appropriate tourist destination, highly respecting expectations and perceptions of sophisticated cultural visitors, will have to respond in a qualitative and thoughtful way to newly emerging cultural needs by using some innovative and sustainable solutions (Petkova \& Marinov, 2014). One of them could be relying on reliable models for finding insufficiently integrated domains of cultural tourism service, taking into account the whole process of its creation and contributing developmental elements.

Unlike other conceptual models of classification of cultural tourism diversification forms (Csapo, 2012), this study model offers better explanation of mutual relations from the generic aspect, pointing to the chronological dimension and strength of their connection. Having in mind the analyzed dimensions of the structural and morphological connection of diversification forms of the contemporary cultural tourism offer, it is possible to examine and re-examine the appropriateness, as well as the consequences of further developmental path in the field of cultural tourism. Accordingly, it is right justifiable to ask whether diversification forms of cultural tourism at the global level represent a current development trend or just the beginning of self-disappearing - and try to give as more objective and thoughtful answer to the highlighted dilemma. The sources for the mentioned dilemma lie in the pronounced fragmentation of cultural tourist values at the destination offer's level (Smith, 2015).

\section{REFERENCES}

Ashworth, G., \& Page, S.J. (2011). Urban tourism research: Recent progress and current paradoxes. Tourism Management, 32(1), 1-15. DOI:10.1016/j.tourman.2010.02.002

Barbieri, C., \& Mahoney, E. (2010). Cultural tourism behavior and preferences among the live-performing arts audience: An application of the univorous-omnivorous framework. International Journal of Tourism Research, 12(2010), 481-496. DOI:10.1002/jtr.767

Benur, A.M., \& Bramwell, B. (2015). Tourism product development and product diversification in destinations. Tourism Management, 50, 213-224. DOI:10.1016/j.tourman.2015.02.005

Chen, H., \& Rahman, I. (2018). Coultural tourism: An analysis of engagement, cultural contact, memorable tourism experience and destination loyalty, Tourism Management Perspectives, 26, 153-163. DOI:10.1016/j. tmp.2017.10.006

Christou, E. (2005). Heritage and cultural tourism: A marketing focused approach. In M. Sigala, D. Leslie (eds), International cultural tourism: Managements, implications and cases (pp. 3-15). Oxford, UK: ButterworthHeinemann.

Csapo, J. (2012). The role and importance of cultural tourism in modern tourism industry. In M. Kasimoglu \& H. Aydin (eds), Strategies for tourism industry (pp. 201-232). Rijeka, Croatia: In Tech.

Domšić, L. (2013, September). Cultural heritage and identity in the contemporary tourism development. In DIEM: Dubrovnik International Economic Meeting (Vol. 1, No. 1, pp. 0-0). University of Dubrovnik, Croatia.

Hughes(1996).Redefiningculturaltourism.AnnalsofTourismResearch,23(3),707-709.https://doi.org/10.1016/0160 -7383(95)00099-2

Hughes, H.L., \& Allen, D. (2005). Cultural tourism in Central and Eastern Europe: The views of 'induced image formation agents'. Tourism Management 26:173-183. https://doi.org/10.1016/j.tourman.2003.08.021

International Council on Monuments and Sites-ICOMOS. (2002). ICOMOS International cultural tourism charter. ICOMOS International Scientific Committee on Cultural Tourism. http://www.charts-interreg4c.eu/app/download/5796628919/ICOMOS+International+Cultural+Tourism+Charter+1999.pdf 
Kay, P.L. (2009). Cultural experience tourist motives dimensionality: A cross-cultural study. Journal of Hospitality Marketing and Management, 18(4), 329-371. https://doi.org/10.1080/19368620802590217

Mc Kercher, B., Ho, P.S.Y., Du Cross, H., \& So-Ming, B.C. (2008). Activities-based segmentation of the cultural tourism market. Joural of Travel and Tourism Marketing, 12(1), 23-46. https://doi.org/10.1300/ J073v12n01_02

Mc Kercher, B., \& Du Cross, H. (2003). Testing a cultural tourism typology. International Journal of Tourism Research, 5(2003), 45-58. https://doi.org/10.1002/jtr.417

Mc Kercher, B., \& Du Cross, H. (2002). Cultural Tourism. Oxford, UK: Claredon Press.

Medina, L.K. (2008). Ecotourism and certification: Confronting the principles and pragmatics of socially responsible tourism. Journal of Sustainable Tourism, 13(3), 281-295. https://doi.org /10.1080/01434630508668557

Moscardo, G. (2001). Cultural and heritage tourism: The great debates. London, UK: Continuum.

Organization for Economic Co-operation and Development-OECD. (2009). The impact of culture on tourism. Paris, France: OECD. http://www.em.gov.lv/images/modules/items/OECD_Tourism_Culture.pdf

Otto, J.E., \& Ritchie, J.R.B. (1996). The service experience in tourism. Tourism Management, 17(3), 165-174. https://doi.org/10.1016/0261-5177(96)00003-9

Petkova, E., \& Marinov, V. (2014). Development of diversified tourism destination products: A case study of tourism destination, Municipality of Sofia, Bulgaria. Journal of Environmental and Tourism Analyses, 2(1), 33-47.

Pritchard, A., \& Morgan, N.J. (2001). Culture, identity and tourism representation: Marketing Wales or Cymru? Tourism Management, 22(2), 167-179. https://doi.org/10.1016/S0261-5177(00)00047-9

Richards, G. (2001). Cultural attractions and European tourism. Wallingford, UK: CABI Publishing.

Ritchie, B. W. (2003). An introduction to educational tourism. Managing educational tourism, 1-24.

Smith, M. K. (2015). Issues in cultural tourism studies. London, UK: Routledge.

Tala, M.L., \& Padurean M. (2008). Dimensions of religious tourism. Amfiteatru Economic, 10, 242-253.

Tomljenović, R., \& Dukic, L. (2017, January). Religious tourism: From a tourism product to an agent of societal transformation. In: SITCON- Singidunum International Tourism Conference. Singidunum University, Serbia. https://bib.irb.hr/datoteka/902067.1-8.pdf

Tourism Business Essentials. Destination British Columbia (2014). Cultural and heritage tourism development [online]. Retrieved from https://www.destinationbc.ca/getattachment/Programs/Guides-Workshopsand-Webinars/Guides/Tourism-Business-Essentials-Guides/TBE-Guide-Cultural-and-Heritage-Tourism-Jan2014.pdf.aspx

Trauer, B. (2006). Conceptualizing special interest tourism: Frameworks for analysis. Tourism management, 27(2), 183-200. https://doi.org/10.1016/j.tourman.2004.10.004

United Nations Educational, Scientific and Cultural Organization- UNESCO. (2006). Tourism, culture and sustainable development [online]. Retrieved from http://unesdoc.unesco.org/images/0014/001475/147578e. pdf

Urošević, N. (2012). Cultural identity and cultural tourism - Between the local and the global (a case study of Pula, Croatia). Singidunum Journal of Applied Sciences, 9(1), 67-76.

Vana, M.V., \& Maleascu S. (2016). Cultural thematic tourism itineraries: Mediators of success. Procedia Economics and Finance, 39(2016), $642-652$.

Weidenfeld, A. (2018). Tourism diversification and its implications for smart specialisation. Sustainability, 10(2), 1-24. https://dx.doi.org/10.3390/su10020319

Yang, L. (2011). Ethnic tourism and cultural representation. Annals of Tourism Research, 38(2), 561-585. https://doi.org/10.1016/j.annals.2010.10.009 